\title{
Erratum to: Geographical variation in body size and sexual size dimorphism of introduced American bullfrogs in southwestern China
}

\author{
Xuan Liu $\cdot$ Yiming Li $\cdot$ Monica McGarrity
}

Published online: 29 October 2009

(C) Springer Science+Business Media B.V. 2009

\section{Erratum to: Biol Invasions \\ DOI 10.1007/s10530-009-9606-1}

Unfortunately, first two author's given name and family name had been wrongly published. The correct version is Xuan Liu not Liu Xuan and Yiming Li not Li Yiming as published.

The online version of the original article can be found under doi:10.1007/s10530-009-9606-1.

X. Liu · Y. Li $(\bowtie)$

Key Laboratory of Animal Ecology and Conservation Biology, Institute of Zoology, Chinese Academy

of Sciences, 1 Datun Beichen West Road, Chaoyang,

Beijing 100101, China

e-mail: liym@ioz.ac.cn

\section{Liu}

Graduate University of Chinese Academy of Sciences,

19 Yuquan Road, Shijingshan, Beijing 100039, China

M. McGarrity

Gulf Coast Research and Education Center, University of Florida/IFAS, 1200 North Park Road, Plant City,

FL 33563, USA 